\title{
A produção histórica do espaço portuário da cidade do Rio de Janeiro e o projeto Porto Maravilha
}

Correspondência entre os grandes ciclos de acumulação capitalista e as morfologias urbanas

La production historique de l'espace portuaire de la ville de Rio de Janeiro et le projet Porto Maravilha : la correspondance entre les grands cycles

d'accumulation capitaliste et les morphologies urbaines

The historical production of the harbour space of Rio de Janeiro and the Porto Maravilha project: correspondence between great cycles of capitalist accumulation and urban morphologies

La produccíon histórica del espacio portuario de la ciudad de Rio de Janeiro y el Proyecto Puerto Maravilla: correspondencia entre los grandes ciclos de acumulación capitalista y las morfologías urbanas

\section{Letícia de Carvalho Giannella}

\section{(2) OpenEdition}

Journals

Edição electrónica

URL: http://journals.openedition.org/espacoeconomia/445

DOI: $10.4000 /$ espacoeconomia.445

ISSN: 2317-7837

\section{Editora}

Núcleo de Pesquisa Espaço \& Economia

\section{Refêrencia eletrónica}

Letícia de Carvalho Giannella, « A produção histórica do espaço portuário da cidade do Rio de Janeiro e o projeto Porto Maravilha », Espaço e Economia [Online], 3 | 2013, posto online no dia 19 dezembro 2013, consultado o 30 abril 2019. URL : http://journals.openedition.org/espacoeconomia/445; DOI : 10.4000/espacoeconomia.445

Este documento foi criado de forma automática no dia 30 Abril 2019. 


\section{A produção histórica do espaço portuário da cidade do Rio de Janeiro e o projeto Porto Maravilha}

Correspondência entre os grandes ciclos de acumulação capitalista e as morfologias urbanas

La production historique de l'espace portuaire de la ville de Rio de Janeiro et le projet Porto Maravilha : la correspondance entre les grands cycles d'accumulation capitaliste et les morphologies urbaines The historical production of the harbour space of Rio de Janeiro and the Porto Maravilha project: correspondence between great cycles of capitalist accumulation and urban morphologies La produccíon histórica del espacio portuario de la ciudad de Rio de Janeiro y el Proyecto Puerto Maravilla: correspondencia entre los grandes ciclos de acumulación capitalista y las morfologías urbanas

Letícia de Carvalho Giannella

\section{Introdução}

1 O presente artigo procura trazer à luz os processos que vêm engendrando o espaço portuário do Rio de Janeiro ao longo de sua história, com base na correspondência entre os ciclos seculares de acumulação capitalista analisados por Arrighi (1996) e as morfologias urbanas observadas na área. Com isto, estamos traçando um paralelo com o artigo de Fernandes (2008) a respeito da evolução da morfologia urbana da cidade do Rio de Janeiro como um todo, a partir de um olhar mais específico para os bairros que configuram sua zona portuária (em especial, Saúde, Gamboa e Santo Cristo). Sendo assim, abordaremos as mudanças sofridas pela área em questão ao longo dos "quatro grandes 
ciclos de acumulação e de gestão do território e da cidade: o século XVIII, com o mercantilismo e a gestão policial; o século XIX, com o liberalismo; o século XX, com o fordismo-keynesianismo; e, finalmente, o período pós-1970, com o neoliberalismo" (Fernandes, op.cit., não paginado).

2 O trabalho é pensado em um contexto de transformações intensas sofridas atualmente pela área em que se inserem, partindo da perspectiva teórica escolhida por nós, na correspondência entre o neoliberalismo e a gestão do território que vem sendo observada nas mais variadas cidades do mundo. Trata-se do Projeto Porto Maravilha, nome fantasia para a Operação Urbana Consorciada (OUC) em questão.

Ressalte-se que, neste artigo, estamos direcionando nosso foco para apenas uma das três dimensões lefebvrianas da produção do espaço. Trata-se do espaço concebido, ou seja, do espaço hegemônico dos planejadores, dos arquitetos e urbanistas, relacionado ao plano das representações, das ideias, do porvir, e cuja operação se dá em um nível abstrato e em uma dimensão técnica e ao mesmo tempo ideológica.

4 O espaço produzido pela ordem hegemônica não é um espaço bem definido, purificado de contradições, a prática espacial não sendo determinada somente pelas representações - o espaço concebido -, mas também pelos espaços de representação - o espaço vivido - que são imprevisíveis, contingentes, cotidianos. Como resultado, a metrópole vai sendo continuamente transformada pelo choque entre o que existe e o que se impõe como novo. Todavia, ainda que saibamos que uma dimensão da produção do espaço não existe isoladamente das demais, isto é, que o processo de produção espacial se dá com base na indissociabilidade entre as três dimensões lefebvrianas, optamos por, no limite deste artigo, voltar nosso olhar para a dimensão do espaço concebido, deixando uma análise mais complexa e abrangente como apontamento para trabalhos futuros.

\section{O espaço portuário do Rio de Janeiro e o Estado mercantilista}

5 Foucault (2008) apresenta o Estado mercantilista do século XVIII como um Estado policial, no qual a polícia teria seu sentido mais amplo e deveria ocupar-se dos seguintes elementos:

A religião; os costumes; a saúde e os meios de subsistência; a tranquilidade pública; o cuidado com os edifícios, praças e caminhos; as ciências e as artes liberais; o comércio, as manufaturas e as artes mecânicas; os empregados domésticos e os operários; o teatro e os jogos; enfim o cuidado e a disciplina dos pobres, como parte considerável do bem público (2008, p. 450).

6 Ou seja, a polícia trataria de questões que são urbanas e mercantis, imbricando-se também na esfera privada. "Daí o fato de que a polícia nos séculos XVII e XVIII foi, a meu ver, essencialmente pensada em termos do que poderíamos chamar de urbanização do território" (Foucault, op. cit.,, p. 452).

7 Tal configuração resulta na produção de espaços urbanos que pudessem ser pertinentemente direcionados para a disciplinarização e regulamentação. É nesse contexto que se desenvolve o urbanismo barroco, que tratou de clarificar o espaço a fim de dar visibilidade à vigilância e ao poder do Estado abrindo avenidas, praças, jardins, construindo fortalezas e monumentos. 
8 Esse movimento, contudo, acabou por consistir, na maior parte dos casos, em transformações de porções do espaço restritas das cidades tanto europeias como coloniais, ainda que seus reflexos fossem visíveis por toda a cidade. "Nem sempre era possível planejar toda uma cidade nova ao estilo barroco, mas, no traçado de meia dúzia de novas avenidas ou de um bairro novo, seu caráter podia ser redefinido" (Munford, 1982, p. 399).

9 O Rio de Janeiro pode ser tomado como um exemplo dessa constatação, uma vez que as reformas barrocas realizadas em localidades específicas do centro da cidade foram acompanhadas por transformações que refletiram na cidade como um todo.

É interessante notar que o próprio mercado de escravos foi transferido, naquele momento, da Rua Direita, no centro da cidade, para o Valongo, enseada situada no atual bairro da Saúde, em nome da higienização e da ordem pública que o urbanismo barroco demandava e "sob a alegação de preservar o espaço urbano do contágio das doenças e epidemias" (Honorato, 2008).

A transferência do mercado de escravos para a região do Valongo foi um importante fator que contribuiu para a dinamização das atividades comerciais e portuárias da região. Significou também um importante marco no processo de especialização espacial da cidade, pois, ao mesmo tempo em que confiava ao Valongo o exercício do comércio negreiro, retirava da Rua Direita uma atividade que não condizia com as atribuições daquela que desde sempre era a principal artéria comercial da cidade (Honorato, op. cit., não paginado).

11 Com base nisso, podemos inferir que a atual zona portuária do Rio de Janeiro era tida, no século XVIII, como uma área isolada e, de certa forma, "não importante" para a cidade, a não ser para o recebimento de uma das atividades mais indesejadas pelas elites que viviam no centro da cidade. As classes hegemônicas eram favoráveis a esse tipo de comércio desde que se realizasse longe de suas vistas.

12 O século XVIII, para o Rio de Janeiro, de acordo com Bernardes (1992), caracterizou-se pelo espraiamento da cidade em três direções: "na planície, para oeste, entre o maciço montanhoso e o alinhamento Conceição-Providência. Ao norte, na faixa de marinha entre esses morros e o mar, e para o sul, a estreita faixa entre as encostas da serra da Carioca e a praia" (p. 43), o que configurou, em linhas gerais, uma luta da cidade contra os brejos e lagoas que dificultavam sua urbanização.

13 Não obstante, tal espraiamento em direção ao norte deu-se de maneira mais espontânea e menos dirigida pelo Estado policial. Poucas foram as ruas abertas naquela área ao longo do século XVIII que fossem retilíneas e amplas, como é o caso da Rua do Livramento, que ligava a enseada do Valongo à enseada da Gamboa. O que se observou foi mais uma relativamente rápida expansão das construções urbanas naquela faixa costeira. Inclusive, muito daquele traçado pode ser visto ainda hoje em visitas à área.

14 Assim sendo, produziu-se o espaço portuário em questão de maneira mais espontânea e deixada de lado pela gestão policial do Estado, que teria centrado seus esforços nas transformações do centro da cidade em si. Essa produção espacial espontânea iria intensificar-se no século seguinte, mas desta vez tendo como sustentação a "mão invisível do mercado" do período liberal. 


\section{O espaço portuário do Rio de Janeiro e o Estado liberal}

15 A representação que a população possuía e possui, até os dias atuais, da zona portuária da cidade passa por imagens de degradação, sujeira, violência, velhice, escuridão. Aqui pretendemos evidenciar, ainda que superficialmente, como se deu aprodução dessa "degradação" durante o século XIX, destacando-se que este não é um processo restrito ao Rio de Janeiro, mas que se expressou também em cidades as mais diversas, como Londres e Paris. Abordaremos também brevemente aquela que foi a grande tentativa de retomada do controle do Estado sobre o planejamento urbano a fim de acabar com a propalada "degradação", conhecida como Reforma Passos.

O predomínio do Estado liberal relaciona-se, segundo Arrighi (1996), à hegemonia britânica e ao imperialismo de livre comércio. Naquele momento houve, em cada parte do mundo capitalista, um nítido recuo do Estado e um comando das ações e relações sociais que produzem o espaço pela burguesia que se consolidava. Nesse contexto, o planejamento urbano que se verificava no período da gestão policial dos territórios foi parcialmente abandonado e deu lugar a uma prática urbanística que esteve voltada unicamente para a satisfação dos interesses e estratégias do capital industrial insurgente.

Fernandes (2008, não paginado) acredita que esse período pode ser subdividido em dois momentos: o primeiro, caracterizado pela entrega quase total das cidades à prática do laissez-faire que vinha sendo incentivada pelos economistas liberais; e o segundo, caracterizado pelas reformas urbanas que se deram da segunda metade do século XIX até o início do século XX e que visavam romper os estigmas da "cidade da noite apavorante" (Hall, 2007).

Note-se que esse processo de ocupação da zona portuária do Rio de Janeiro, iniciado mais timidamente no século anterior, deu-se com base nos interesses privados dos cafeicultores do Vale do Paraíba, articulados ao mercado mundial - principalmente após a abertura dos portos -, e através de alianças com os setores industriais relacionados principalmente com as atividades ferroviárias e portuárias.

19 Foi a zona portuária do Rio de Janeiro que abrigou também a primeira favela da cidade: a da Providência, situada no morro de mesmo nome, entre os bairros da Gamboa e Santo Cristo. Em 1897, os soldados republicanos regressos da Guerra de Canudos territorializaram-se naquela localidade e deram início à sua ocupação.

Começava a consolidar-se assim a cidade liberal por excelência, caracterizada pela transferência das classes altas para os "aprazíveis" subúrbios distantes e das classes médias para zonas intermediárias, e pela concentração da população pobre nas áreas centrais, tidas como degradadas e insalubres.

21 Entretanto, localizavam-se também na área central do Rio de Janeiro - em especial na zona portuária - o terminal ferroviário, o porto e as instalações mercantis da cidade, de modo que a situação descrita pouco a pouco tornava-se insustentável perante as elites que necessitavam daquela área para o desenvolvimento de suas próprias atividades. Assim sendo, a demanda pela reforma urbana revelava-se imperiosa. As velhas formas da área central da cidade e adjacências iam pouco a pouco se tornando incompatíveis com as novas funções que adquiriam. 
22 Após a elaboração de sete projetos de reformas que não se concretizaram, vem à tona a reforma de Pereira Passos, realizada no início do século XX. O porto do Rio de Janeiro, tal como o conhecemos hoje, foi inaugurado oficialmente em 1910, depois de sete anos de obras que retilinizaram a costa aterrando uma área de $175.000 \mathrm{~m}^{2}$ com entulho proveniente do arrasamento do morro do Senado. "As palavras de ordem passaram a ser modernizar, higienizar, civilizar. Era preciso renovar, reformar, regenerar a cidade" (Cardoso et. al.,, 1987, p. 100).

23 Como resultado da reforma, podemos hoje verificar "duas" zonas portuárias da cidade que praticamente não se comunicam: a primeira delas é a "parte alta" dos morros, que sempre esteve ali e que começou a ser ocupada ainda nos séculos XVII e XVIII, composta por diversas territorialidades; a segunda é a "parte baixa", ou seja, o aterro realizado a partir do arrasamento do Morro do Senado para expansão do porto em si. Esta última acabou sendo ocupada - principalmente após o deslocamento das atividades portuárias para a ponta do Caju, construída na década de 1920 - por atividades e instalações as mais diversas, indo de galpões de escolas de samba até oficinas de automóvel, passando por algumas fábricas expressivas, como o Moinho Fluminense.

24 A reforma urbana levada a cabo por Pereira Passos ainda pode ser contextualizada no período de gestão do território e produção do espaço relacionado ao Estado liberal porque teria estado a cargo prioritariamente das estratégias do capital, ainda que fosse possibilitada pela intervenção estatal: "Seu agente seria o grande capital, cabendo ao Estado apenas a tarefa de conceder os privilégios jurídicos e fiscais para que fosse viável e lucrativo cada componente da operação" (Benchimol, 2002, p. 131). Parece-nos, como veremos adiante, que tal mecanismo se repete hoje.

Segundo Fernandes (2008, não paginado), a reforma Passos seria considerada o marco de uma espécie de transição entre um período fortemente liberal, marcado pelo recuo quase total do Estado no processo de produção do espaço urbano, e um período fordista, caracterizado pela retomada do controle da produção espacial pelo Estado através da intervenção e regulação do espaço urbano.

\section{O espaço portuário do Rio de Janeiro e o Estado fordista}

Giovanni Arrighi (1996) mostra o processo de decadência da hegemonia britânica e de ascensão da hegemonia norte-americana como um movimento que teve início no fim do século XIX e se consolidou após a Primeira Guerra Mundial. Trata-se da terceira hegemonia do capitalismo histórico observada pelo autor. Naquele momento, o centro da hegemonia mundial deslocou-se de Londres para Nova Iorque e a morfologia urbana das cidades norte-americanas passou a ser modelo de gestão do espaço urbano para as mais variadas cidades do mundo, inclusive o Rio de Janeiro.

Por razões óbvias, o paradigma desta cidade foi a cidade produzida nos EUA. Desde os arranha-céus no centro aos subúrbios de suas extensas classes médias promovidos pelo automóvel, passando pelas zonas de obsolescência dos bairros centrais, os shoping centers e operações de renovação urbana, foi ali que se desenhou mais nitidamente a cidade fordista (Fernandes, 2008, não paginado).

27 A zona portuária do Rio de Janeiro, que antes parecia "decolar" com a tão sonhada reforma urbana, sofreu um processo de estagnação após a conclusão da mesma, 
intensificado pela suburbanização não somente das classes médias que se dirigiam cada vez mais para a Zona Sul da cidade, mas também das indústrias e do proletariado que se espraiavam em direção à Zona Norte e à Zona Oeste, inclusive estimulados pela produção estatal de conjuntos habitacionais em bairros como Realengo, Bangu e Marechal Hermes (Fernandes, 2008, não paginado). Sendo assim,

os bairros portuários ficaram, de certa maneira, à margem da cidade, no tempo e no espaço. [...]. Esse isolamento seria acentuado a partir de meados do século, devido a importantes intervenções urbanísticas promovidas pelo poder público. À margem até do porto, uma vez que o grande aterro afastou definitivamente os antigos bairros marítimos do mar, e as áreas aterradas nunca chegaram a se integrar realmente com as áreas antigas. Os elos que promoviam a ligação com a cidade iam sendo rompidos lentamente, isolando aos poucos os três antigos bairros portuários (Cardoso et. al., 1987, p. 128). fordista que, segundo Harvey (1992, p. 135), tornara-se fato entre 1965 e 1973 à medida que se evidenciava cada vez mais a incapacidade daquele regime "de conter as contradições inerentes ao capitalismo". A rigidez estatal do fordismo deu passagem à acumulação flexível do capital que, por sua vez, mais tarde teria germinado o Estado neoliberal. Esta passagem caracteriza-se por um quase apagamento dos compromissos do Estado com o bem-estar social, uma vez que é instalada uma cultura do empreendedorismo que se volta para um individualismo competitivo que enfraquece as associações de classe construídas no período fordista, bem como as lutas sociais coletivas. Essa flexibilização do capital, suas consequências e condições sine qua non vêm acompanhando desde então as mais distintas esferas da vida, inclusive a administração municipal. É nesse contexto empreendedor que se insere a chamada "guerra dos lugares" (Santos, 1997; Carlos, 2007) e o desenvolvimento das propostas e projetos de revitalização de áreas centrais e zonas portuárias nas mais diversas cidades do globo. Tais propostas vêm sendo desenhadas com base na preparação de áreas específicas das cidades para a atração de investimentos privados que tenham a capacidade de transformá-las segundo os interesses das classes hegemônicas próximas e distantes, bem como de movimentar o capital financeiro transnacional e global. 
33 A próxima e última sessão deste artigo apresenta brevemente como esse modelo de planejamento urbano relacionado ao Estado neoliberal reflete-se no processo atual de transformação da zona portuária da cidade do Rio de Janeiro.

\section{O espaço portuário do Rio de Janeiro e o Estado neoliberal: o Projeto Porto Maravilha}

34 Existem propostas de reforma urbana da zona portuária do Rio de Janeiro desde pelo menos 1983, ainda que todas tenham sido pouco ou nada concretizadas. A primeira tentativa resultou na criação do projeto SAGAS (Saúde, Gamboa e Santo Cristo), em 1988, quando moradores da área viram-se ameaçados de remoção em massa e, uma vez mobilizados, pressionaram a Prefeitura municipal a fim de que fossem desenvolvidos projetos com objetivos conservacionistas. ${ }^{1}$ Entre 1983 e 2001, foram sete os planos elaborados para a transformação ou do porto ou da zona portuária como um todo ${ }^{2} \mathrm{o}$ último deles (Porto do Rio) representando já fortemente o desejo de se tratar a cidade como uma forma de empreendimento através de mecanismos de parcerias públicoprivadas. As propostas ali contidas são bastante similares às propostas do Projeto Porto Maravilha; todavia, naquele momento não havia a necessária identificação política entre as esferas de governo, o que esbarrava na existência de questões fundiárias impeditivas para a concretização das ideias. ${ }^{3}$ Acredita-se, também, que faltou mobilização da sociedade como um todo em torno do projeto. Poderíamos dizer que a capacidade de convencimento e criação de consenso por meio da mídia não tenha sido tão efetiva quanto a que vemos atualmente no que se refere ao Projeto Porto Maravilha. Como um último, mas nem de longe menos importante, fator decisivo para a concretização do Projeto no momento atual encontramos a articulação do mesmo com a proximidade da Copa do Mundo de 2014 e dos Jogos Olímpicos de 2016, megaeventos responsáveis por significativo aporte de recursos advindo dos setores privados e das outras esferas de governo, principalmente a federal.

Em meados de 2010 foi noticiado pela Companhia de Desenvolvimento Urbano da Região do Porto (CDURP, sobre a qual discutiremos mais adiante) que o Comitê olímpico Internacional (COI) havia aprovado a instalação na zona portuária de boa parte da Vila de Mídia, a ser construída na Avenida Francisco Bicalho. O COI teria ainda lançado a possibilidade de, nesse contexto de revitalização urbana, serem alocadas outras instalações necessárias para os jogos e cujas localizações ainda não houvessem sido escolhidas. Mais tarde, entre o final de 2012 e início de 2013, foi lançado pelo Instituto dos Arquitetos do Brasil (IAB) o concurso Porto Olímpico, com patrocínio da Prefeitura Municipal do Rio de Janeiro, através do Instituto Pereira Passos (IPP), e apoio do Comitê Organizador dos Jogos Olímpicos de 2016, que determinou a instalação na área não mais de parte da Vila de Mídia apenas, mas também da Vila de Árbitros, de hotéis e do Centro de Exposições e Convenções, que abrigará setores operacionais dos eventos (Concurso Porto Olímpico).

Destaca-se que essa tendência de direcionamento dos planejamentos para as áreas centrais e portuárias das cidades coexiste com a suburbanização característica do período fordista e a definição de novas centralidades urbanas, com a diferença temporal, no Rio de Janeiro, de duas décadas entre a origem de ambas. Isto significa que o processo de suburbanização das classes médias e altas iniciado com a expansão urbana em direção à 
Zona Sul da cidade na primeira metade do século XX teve continuidade, nos anos 1970, com a expansão da malha urbana em direção à Barra da Tijuca. Entretanto, essa nova leva de suburbanização se deu com base na elaboração de um plano urbanístico de autoria de Lucio Costa cuja referência direta estava nos novos bairros suburbanos verticalizados que surgiam nas cidades norte-americanas e que minavam a cidade como uma possibilidade das coexistências e convivências sociais. Ao mesmo tempo, a área central seguia perdendo importância perante o contexto da cidade como um todo, até o momento em que os sujeitos públicos e privados voltaram a perceber a potencialidade econômica daquelas áreas com base na visualização de resultados de intervenções urbanas de "sucesso" em outras cidades semelhantes. Tal "retorno ao centro" começou a ser desenhado no final da década de 1980.

Para tornar a cidade competitiva, aposta-se na formação de parcerias público-privadas em que, segundo Harvey (2006, p. 172), “[...] a iniciativa tradicional local se integra com o uso dos poderes governamentais locais, buscando e atraindo fontes externas de financiamento, e novos investimentos diretos ou novas fontes de emprego".

Outra característica desse direcionamento das políticas urbanas que pode ser destacada é a "transferência de técnicas de gestão empresarial à administração urbana - como o marketing e o planejamento estratégico [...]", o que implica a reificação da cidade como empresa e, simultaneamente, mercadoria (Compans, 2005, p. 26). o discurso é o responsável por construir as representações que naturalizam esse processo.

Uma das experiências à qual os gestores urbanos mais se referem com reverência é a de Barcelona, que transformou sua zona portuária degradada em um centro de atração turística, negócios e lazer e cujo resultado seria de grande sucesso (para quem?). Sendo assim, Barcelona segue sendo o modelo de revitalização de áreas centrais e portuárias, principalmente para as cidades latino-americanas. Porém, segundo Claver (2006), o poder público promoveu um tipo de centro urbano orientado para o consumo e especializado por zonas sem se preocupar com a oferta de habitações populares, o que acaba gerando segregação socioespacial na área (p. 163). Ao que parece, o modelo de intervenção do Projeto Porto Maravilha segue a mesma cartilha.

O projeto foi criado oficialmente com o Projeto de Lei Complementar (PLC) n²5/2009, que modifica o Plano Diretor e autoriza a instituição da Operação Urbana Consorciada (OUC) da Região do Porto do Rio. A lei baseia-se na Área de Especial Interesse Urbanístico (AEIU) da Região do Porto do Rio, delimitando a área de atuação da OUC, que compreenderia um conjunto de reestruturações urbanas da região em questão. A primeira diretriz assumida no projeto de lei quanto à OUC diz respeito ao estímulo à transformação gradativa do uso portuário de cargas em usos residencial, comercial, de serviços, cultural e de lazer, o que vem ao encontro dos modelos de reformas aplicados em outras cidades do mundo, como Barcelona.

Chama-nos a atenção também nesse projeto de lei, afora os itens anteriormente destacados, os instrumentos que serão utilizados para implementação da OUC: "instituição de parcerias entre o poder público e o setor privado", "consórcios públicos", "utilização de instrumentos de mercados de capitais" e "instrumentos de política urbana previstos no Estatuto da Cidade e no Plano Diretor Decenal da Cidade do Rio de Janeiro". Quanto à alteração do Plano Diretor, a lei possibilita a Outorga Onerosa do Direito de Construir e de Alteração de Uso do Solo, permitindo o estabelecimento de índices diferenciados dentro do perímetro definido para realização da OUC, podendo determinar índices de aproveitamento de terreno superiores aos definidos no Plano Diretor, índices 
esses que passam a ser denominados Coeficientes de Aproveitamento Máximo. Além disso, o PLC 25 altera o Plano Diretor ao acrescentar-lhe a autorização de usos não permitidos atualmente para o local mediante o pagamento de contrapartida por Outorga Onerosa de Alteração de Uso. $O$ instrumento de Outorga Onerosa de Construção se dará através da venda dos Certificados de Potencial Adicional de Construção (Cepac). Estes permitirão a construção de edifícios com gabaritos de até 50 andares na Avenida Francisco Bicalho e no setor norte, seguindo a linha do cais do porto, próximo ao Terminal Rodoviário Novo Rio, o que apagará definitivamente da História essas porções do espaço, bem como a vista livre dos morros da região.

O último ponto a ser destacado do texto do PLC 25 trata da criação do Conselho Consultivo, que terá competência (somente) para emitir pareceres sobre os relatórios trimestrais da Companhia de Desenvolvimento Urbano da Região do Porto do Rio de Janeiro (CDURP). O que nos parece grave em relação ao Conselho, além de sua competência, é sua composição, a ser formada por um representante da CDURP, como coordenador; dois representantes do município; e dois representantes da sociedade civil a serem escolhidos pelos demais integrantes do Conselho, com mandato de três anos.

43 A CDURP, por sua vez, consiste em uma sociedade de economia mista, autônoma, em forma de sociedade por ações, coordenada pelo município e criada pelo Projeto de Lei Complementar n²6/2009. Sua criação configura um enclave territorial, uma vez que a Companhia passa a ser responsável pela gestão de serviços de interesse local e serviços públicos de competência municipal, como paisagismo, limpeza urbana, coleta de resíduos sólidos, drenagem de águas pluviais, iluminação pública etc. No parágrafo terceiro do PLC que a cria lê-se que "a CDURP deverá obedecer a padrões de governança corporativa", deixando clara a adoção do modelo de planejamento estratégico de cidades para revitalização da zona portuária do Rio de Janeiro.

Importa observar também como os autores do projeto em questão enxergam a área a ser afetada pela Operação. Para isso, retomamos a ideia de que a Reforma Passos teria produzido "duas" zonas portuárias distintas e quase incomunicáveis entre si.

A OUC que é objeto de nossa análise, ao que nos parece, considera a área plana da expansão do porto uma espécie de tabula rasa, ou seja, o que está proposto para aquela porção do espaço é a demolição dos galpões e barracões preexistentes para a construção de edifícios comerciais cujo gabarito pode variar de 20 andares para o setor mais próximo à Praça Mauá a 50 andares ao longo da Avenida Francisco Bicalho. Também para essa área está prevista a demolição parcial da Avenida Perimetral no trecho que se inicia na direção do Mosteiro de São Bento até a Rodoviária Novo Rio, a construção de uma garagem subterrânea na Praça Mauá e de uma via paralela à Rodrigues Alves, cujo nome será Binário do Porto e que pretende receber o chamado VLT (veículo leve sobre trilhos). 0 píer Mauá, já em obras, receberá o Museu do Amanhã, em parceria com a Fundação Roberto Marinho (e cujo projeto - somente o projeto -, do renomado arquiteto espanhol Calatrava, estabelece um orçamento de cerca de $\mathrm{R} \$ 20.000 .000,00)$. Se o leitor visitar o sítio eletrônico do projeto Porto Maravilha hoje, verá que as únicas propostas concretas de intervenção na área, com exceção de algumas obras de infraestrutura urbana que já podem ser observadas ao longo das Avenidas Barão de Tefé e Rodrigues Alves, referem-se aos chamados projetos-âncora, que são os empreendimentos culturais pontuais que supostamente atrairão investidores privados para revitalização completa da área. Entre eles, além do Museu do Amanhã, encontra-se a restauração da Igreja de São Francisco da Prainha, situada no Morro da Conceição; a restauração, também já em andamento, do 
edifício “A Noite" e do Palacete D. João VI (transformado no Museu de Arte do Rio - MAR), situados na Praça Mauá; e a construção do AquaRio (o mais moderno aquário da América Latina, fruto de investimento totalmente privado) em um dos armazéns da antiga área de operação do porto.

Tais ações caracterizam uma espécie de apagamento da história daquela porção do espaço, uma vez que, no contexto atual de inserção das cidades no mercado global,

é preciso dotar o espaço urbano de um conjunto de representações e situações capazes de constituir lugares excitantes, atraentes, criativos e ao mesmo tempo seguros para investir, jogar, apostar e consumir. Esse processo de reestruturação urbana vem impondo às cidades um catálogo de formas repetitivas e diluidoras das diferenças socioculturais qualitativas (Barbosa, 2006, p. 129).

Isto acontece ao mesmo tempo em que, no plano do discurso, é valorizado o resgate das identidades culturais e da memória das populações que habitam aquela área. É necessário aqui remeter-nos à outra zona portuária "isolada" pela Reforma Passos, a "parte alta" que até o final do século XIX configurava o desenho litorâneo sinuoso das reentrâncias do porto e da Baía de Guanabara. Tal porção da área caracteriza-se marcadamente pela presença dos morros que a desenham. São eles: Morro da Conceição, Morro da Providência/Santo Cristo e Morro do Pinto.

Podemos dizer que, basicamente, o projeto tem se voltado para a transformação do Morro da Conceição em uma área atraente para a atividade turística; para a urbanização do Morro da Providência, o que inclui a instalação de um teleférico, um plano inclinado e diversas praças; e para a transformação das vias do entorno com a finalidade de promover melhorias na circulação de automóveis e a construção do corredor para o VLT. Até o momento, não encontramos qualquer informação a respeito do Morro do Pinto e adjacências. O Morro da Conceição caracteriza-se como

um pequeno bairro histórico cuja ocupação inicial remonta à época colonial, localizado numa colina próxima à Praça Mauá e tendo um casario residencial que, na sua maioria, foi construído no final do século 19 e na primeira metade do século 20. Mais recentemente, o bairro vem ganhando visibilidade na mídia e recebendo a atenção de turistas, fotógrafos, cineastas, produtores de eventos culturais e de outros atores sociais, mas, paradoxalmente, só agora é que instituições públicas estão voltando a cuidar do bairro após décadas de total repúdio, abandono e esquecimento onde o Morro da Conceição gozou de grande invisibilidade junto aos órgãos da Prefeitura, do Governo do Estado e da União (Barbosa e Ossowicki, 2009).

Os autores do trecho citado, moradores do bairro, vêm questionando a maneira como o processo de revitalização vem sendo realizado desde o lançamento do Projeto Porto Maravilha. Para eles, tal prática tem se dado sem qualquer incentivo à participação dos moradores, e a grande questão lançada pelos pesquisadores é:

Será que o IPHAN, ${ }^{4}$ ao invés de se preocupar com a preservação dos espaços de convívio e das memórias sociais e suas relações múltiplas com fachadas, ruas, becos e escadarias, estaria se dedicando apenas a um tipo de salvaguarda que mistura antigas práticas monumentalistas baseadas na contemplação estética das elites culturais com a tendência atual de transformar patrimônios em novas mercadorias a serem, simplesmente, consumidas?

De fato, tal receio procede, uma vez que projetos de revitalização similares têm provocado uma espécie de museificação que acaba por gerar uma expulsão de populações locais e substituição das mesmas por uma população de classe média desejosa da experiência de habitar ou lançar empreendimentos comerciais em um ambiente bucólico e charmoso..$^{5}$ Esse foi o caso da revitalização do Pelourinho, em Salvador, ${ }^{6}$ e temos 
observado algo semelhante no bairro carioca da Lapa. O Morro da Conceição configura uma condição sui generis devido ao fato de ser habitado tanto por uma população pobre e muito antiga, descendente dos portugueses que ali chegaram no século XIX, quanto por artistas que podem, por um viés, desejar a transformação do bairro em um produto turístico.

51 No que se refere ao Morro da Providência, a impressão que tivemos em nossas visitas de campo e a partir da participação no Fórum Comunitário do Porto é de que a justificativa para a realização de obras por toda a favela é o Projeto Morar Carioca, que de uma forma ou de outra acabou sendo atrelado ao Porto Maravilha. Contudo, está-se desconsiderando nesse processo qualquer respeito ao direito à informação e à moradia.

Não nos alongaremos quanto a esse assunto devido ao limite de espaço deste artigo, mas podemos dizer que o Projeto Porto Maravilha, mesmo ao considerar em suas propostas o espaço construído, no que se refere à área que estamos chamando de "parte alta", vem desconsiderando a dimensão do espaço vivido das populações que habitam a área. Tal questão será mais bem estudada e fica aqui como um apontamento para trabalhos futuros.

53 Sendo assim, podemos dizer que a proposta atual de revitalização da zona portuária do Rio de Janeiro cumpre um ideário neoliberal de ordenamento das cidades a partir do incentivo à iniciativa privada, à estetização do espaço e ao sufocamento dos espaços vividos e das territorialidades das populações que habitam a área. Tendo em vista tal configuração, tecemos a hipótese de que o espaço que se produzirá será um espaço voltado para o desencontro mais do que para o encontro, para anulação das diferenças mais do que para a convivência com a diversidade, para satisfação de outros que não aqueles que têm participado ativamente da produção histórica daquela porção do espaço. Acreditamos, todavia, no potencial dos movimentos sociais que têm se organizado para resistir às propostas tal como vêm sendo colocadas e para propor alternativas ao projeto.

\section{Para não concluir. em busca de novos apontamentos}

54 A zona portuária do Rio de Janeiro caracteriza-se por ser uma área historicamente produzida sem que tenha havido qualquer preocupação do Estado quanto à satisfação das necessidades e anseios das suas diversas populações. Atualmente, assistimos a um processo de intensa transformação de suas territorialidades, o qual está relacionado ao ideário neoliberal de gestão das cidades -- o que significa que continuaremos a observar, em um processo nada novo, a expulsão da memória e da história daquele espaço, a partir da expulsão de quem a produz no cotidiano.

O presente trabalho procurou apontar para a construção histórica da zona portuária da cidade com base nos ciclos seculares de acumulação capitalista, o que configura uma abordagem que podemos chamar de "oficial". Resta como novo apontamento o estudo aprofundado dos espaços vividos daquelas populações a fim de que possamos compreender o espaço produzido como um embate entre o concebido e o vivido. Para isso, deixamos como sugestão para futuras investigações também o estudo das resistências e da organização dos grupos sociais que ali vivem em função da proposição de um novo projeto, um novo Porto Maravilha. 


\section{BIBLIOGRAPHY}

ARANTES, O. Uma estratégia fatal: a cultura nas novas gestões urbanas. In: ARANTES, O.; VAINER, C.; MARICATO, E. A cidade do pensamento único. 5ª ed. Petrópolis: Vozes, 2009, p. 11-74.

ARRIGHI, G. O longo século XX: dinheiro, poder e as origens de nosso tempo. Rio de Janeiro: Contraponto, 1996.

BARBOSA, J. L. O ordenamento territorial urbano na era da acumulação globalizada. In: OLIVEIRA, M. P.; HAESBAERT, R.; MOREIRA, R. (orgs.). Território, territórios: ensaios sobre o ordenamento territorial. Rio de Janeiro: DP\&A, 2006, 2ª ed, p. 125-146.

BARBOSA, A. A.; OSSOWICKI, T. M. Revitalização do Porto, IPHAN e políticas culturais no Morro da Conceição. Minha Cidade, ano 9, n. 108/02, 2009. Disponível em: <http://www.vitruvius.com.br/ revistas/read/minhacidade/09.108/1842>. Acesso em: jun. 2010.

BENCHIMOL, J. O haussmanismo na cidade do Rio de Janeiro. In: AZEVEDO, A. (org.). Rio de Janeiro: capital e capitalidade. Rio de Janeiro: EdUERJ, 2002, p. 125-158. BERNARDES, L. Evolução da paisagem urbana do Rio de Janeiro até o início do século XX. In: ABREU, M. (org.). Natureza e sociedade no Rio de Janeiro. Rio de Janeiro: Prefeitura Municipal do Rio de Janeiro, 1992.

CARDOSO, E. D. et al. História dos bairros: Saúde, Gamboa, Santo Cristo. Rio de Janeiro: Índex, 1987.

CARLOS, A. F. O lugar no/do mundo. São Paulo: FFLCH, 2007.

CLAVER, N. A Ciutat Vella de Barcelona: renovação ou gentrificação. In: BIDOU-ZACHARIASEN, C. (org.). De volta à cidade: dos processos de gentrificação às políticas de "revitalização" dos centros urbanos. São Paulo: Annablume, 2006, p. 145-166.

COMPANS, R. Empreendedorismo urbano: entre o discurso e a prática. São Paulo: Unesp, 2005.

CONCURSO PORTO OLÍMPICO. Disponível em:

<http://concursoportoolimpico.com.br/website>. Acesso em: mai. 2011.

FERNANDES, N. N. Capitalismo e morfologia urbana na longa duração: Rio de Janeiro (século XVIII-XXI). In: Scripta Nova. Revista Electronica de Geografia y Ciencias Sociales. Barcelona: Universidad de Barcelona, v. XII, n. 270(56), 2008. Disponível em: <http://www.ub.es/geocrit/sn/ sn-270-56.htm>. Acesso em: ago. 2008.

FÓRUM COMUNITÁRIO DO PORTO. Relatório de violações de direitos e reivindicações.

FOUCAULT, M. Segurança, território e população: curso dado no Collège de France (1977-1978). São Paulo: Martins Fontes, 2008.

HALL, P. Cidades do amanhã: uma história intelectual do planejamento e do projeto urbanos no século XX. São Paulo: Perspectiva, 2007.

HARVEY, D. A produção capitalista do espaço. $2^{\text {a }}$ ed. São Paulo: Annablume, 2006. A condição pós-moderna. São Paulo: Loyola, 1992. 
HONORATO, C. P. Valongo: o mercado de escravos do Rio de Janeiro, 1758 a 1831. 2008. 166p. Dissertação (Mestrado em História). Programa de Pós-Graduação em História. Universidade Federal Fluminense.

LEFÈBVRE, H. La production de l'space. Paris: Anthropos, 1974.

MOREIRA, C. C. A cidade contemporânea entre a tabula rasa e a preservação: cenários para o porto do Rio de Janeiro. São Paulo: Unesp, 2004.

MUNFORD, L. A cidade na história. São Paulo: Martins Fontes, 1982.

PROJETO PORTO MARAVILHA. Disponível em: <http://www.portomaravilhario.com.br>. Acesso em: mai. 2010.

SANTOS, M. A natureza do espaço: técnica e tempo, razão e emoção. $2^{\mathrm{a}}$ ed. São Paulo: Hucitec, 1997.

SOARES, E. M.; MOREIRA, F. D. Preservação do patrimônio cultural e reabilitação urbana: o caso da zona portuária da cidade do Rio de Janeiro. Da Vinci, v. 4, n. 1, 2007, p. 101-120.

SOTRATTI, M. A. Pelas ladeiras do Pelô: a requalificação urbana como afirmação de um produto turístico. 2005, 309p. Dissertação (Mestrado em Geografia). Programa de Pós-Graduação em Geografia. Universidade Estadual de Campinas.

VAINER, C. Pátria, empresa e mercadoria: notas sobre a estratégia discursiva do Planejamento Estratégico Urbano. In: ARANTES, O.; VAINER, C.; MARICATO, E. A cidade do pensamento único. $5^{\mathrm{a}} \mathrm{ed}$ Petrópolis: Vozes, 2009, p. 75-104.

\section{NOTES}

1. O projeto SAGAS foi elaborado a partir do Decreto $\mathrm{n}^{\circ}$ 7.351, de 14 de fevereiro de 1988, e suas principais atribuições são: “a manutenção das características consideradas importantes na ambiência e identidade cultural da área; preservação dos bens culturais que apresentem características morfológicas típicas e recorrentes na área; estabelecimento de critérios para novos gabaritos; prévia aprovação para demolições e construções; criação de um escritório técnico, para fiscalização e acompanhamento das intervenções" (Soares \& Moreira, 2007, p. 108). 2. Não abordaremos aqui cada um dos planos e projetos desenvolvidos, devido à limitação de espaço deste trabalho; para um aprofundamento sobre esta questão, ver Moreira (2004).

3. Cerca de $62 \%$ dos terrenos da zona portuária pertencem à União.

4. Naquele momento inicial de implantação do projeto, o IPHAN foi a instituição mais presente nas visitas ao Morro. Atualmente é notável a ausência do órgão nas discussões sobre o projeto

5. Processo iniciado em Londres e chamado por alguns autores de gentrificação. Arantes (2009) aborda-a como uma estratégia oculta: "Daí a sombra de má consciência que costuma acompanhar o emprego envergonhado da palavra, por isso mesmo escamoteada pelo recurso constante ao eufemismo: revitalização, reabilitação, revalorização, reciclagem, promoção, requalificação, até mesmo renascença, e por aí afora, mal encobrindo, pelo contrário, o sentido original de invasão e reconquista, inerente ao retorno das camadas afluentes ao coração das cidades" (p. 31).

6. Ver dissertação de Sotratti (2005). 


\section{ABSTRACTS}

O espaço portuário da cidade do Rio de Janeiro vem passando por uma reestruturação urbana intensa que pode ser analisada a partir de sua correspondência com o ideário neoliberal. Trata-se do Projeto Porto Maravilha. Entretanto, para compreendermos o processo contemporâneo de transformação desse espaço é importante que o tomemos como um produto histórico. Assim, nosso objetivo é trazer à luz os processos que vêm engendrando o espaço portuário do Rio de Janeiro ao longo de sua história, com base na correspondência entre os ciclos seculares de acumulação capitalista analisados por Giovanni Arrighi (mercantilismo, liberalismo, fordismo/ keynesianismo e neoliberalismo) e nas morfologias urbanas visualizadas na área. Conclui-se que tal espaço caracteriza-se por ter sido historicamente produzido sem que tenha havido, , da parte dos seus agentes produtores hegemônicos, qualquer olhar para os espaços ocupados pelas populações que ali vivem e viveram. Tal prática parece repetir-se no decorrer da elaboração e implementação do Projeto Porto Maravilha.

L'espace portuaire de la ville de Rio de Janeiro connaît une restructuration urbaine intense qui peut être analysée à travers sa correspondance avec l'idéologie néolibérale. Nous aborderons en particulier le projet Porto Maravilha. Cependant, pour comprendre la transformation contemporaine de cet espace, il importe considérer les processus qui ont engendré l'espace portuaire de Rio au fil de son histoire. Pour cela, nous travaillerons sur la correspondance entre les cycles séculaires de l'accumulation capitaliste soulignés par Giovanni Arrighi (mercantilisme, libéralisme, fordisme/keynésianisme et néolibéralisme) et les morphologies urbaines affichées par cette aire. Nous concluons que tel espace se caractérise par la négligence des acteurs hégémoniques envers les espaces vécus par la population résidante. Ces pratiques semblent se prolonger dans le déroulement du projet Porto Maravilha.

The harbor space of Rio de Janeiro knows at present an intense urban restructuration, which can be analyzed by its correspondence with Neoliberal ideology. We'll deal specifically with the Project Porto Maravilha. Nevertheless, to understand the present transformation of this space, it is important to consider the processes which constructed historically the Rio de Janeiro harbor space. For this purpose, we'll work on the correspondence between the secular cycles of capitalist accumulation established by Giovanni Arrighi (Mercantilism, Liberalism, Fordism/Keynesianism and Neoliberalism) and the urban morphologies of this area. We argue that this space is characterized by the negligence of hegemonic actors for the needing of resident population. These practices seem to be continued in the development of the Porto Maravilha project.

El espacio portuario de la ciudad de Río de Janeiro viene pasando por una re-estructuración urbana intensa que puede ser analizada a partir de su vínculo con el ideario neo-liberal. Se trata del Proyecto Puerto Maravilla. No obstante, para comprender la transformación contemporánea de esta área es importante considerar los procesos que han construido el espacio portuario de Río de Janeiro a lo largo de su historia. Para tal efecto, observaremos la correspondencia entre los ciclos seculares de acumulación capitalista trabajados por Giovanni Arrighi (mercantilismo, liberalismo, fordismo/keynesianismo y neo-liberalismo) y las morfologías urbanas que encontramos en la región. Se concluye que tal espacio se caracteriza por la negligencia de los agentes hegemónicos en relación a los espacios vividos por las poblaciones que allí habitan. Tal 
práctica al parecer se repite en el transcurso de la elaboración e implementación del Proyecto Puerto Maravilla.

INDEX

Mots-clés: restructuration, espace portuaire, morphologie urbaine, Rio de Janeiro, Porto Maravilha

Keywords: restructuring, port space, urban morphology

Palabras claves: re-estructuración, espacio portuario, morfología urbana, Puerto Maravilla

Palavras-chave: reestruturação, área portuária

\section{AUTHOR}

\section{LETÍCIA DE CARVALHO GIANNELLA}

Doutoranda em Geografia, Universidade Federal Fluminense. leticiagiannella@gmail.com 